\title{
Die angeblichen Terminalkörperchen an den Haaren einiger Säugethiere.
}

\author{
Von
}

\section{Dr. Ludwig Stieda,}

Prosector und ausserordentlicher Professor in Dorpat.

Kürzlich hat Dr. Jos. Schöbl in Prag eigenthümlich gebaute Körperchen an den Wurzeln der Haare bei Fledermäusen und Hausmäusen beschrieben. Er benennt dieselben bei Fledermäusen Terminalkörperchen, bei Mäusen Nervenknäuel und fasst sie auf als Endorgane sensitiver Nerven (dieses Archiv Bd. Vח; die Flughaut der Fledermäuse, namentlich die Endigung ihrer Nerven pag. 1-32 Taf. I-V und das äussere Ohr der Mäuse als wichtiges Tastorgan pag. 260-268 T'af. XXI-XXIV).

Schon lange mit Untersuchungen der Haut verschiedener Säugethiere beschäftigt, kenne ich auch die in Rede stehenden Gebilde; allein ich bin über dieselben zu einer ganz anderen Anschauung gekommen, als Schöbl. Ich habe bisher es nicht für nöthig erachtet gegen die von Schöbl vorgetragene Deutung aufzutreten, allein jetzt, da seine Ansicht von anderer Seite Unterstützung findet, zögere ich nicht mehr. Es hat sich ein anderer Forscher, nämlich Bol1, mit Entschiedenheit für die Resultate der Untersuenung Schöbl's und dessen Deutung ausgesprochen. Der betreffende Passus lantet im Medicinischen Centralblatt 1871 No. 34 pag. 532 sie folgt: Ref. (Boll) dem sich neulich Gelegenheit bot, diese Angaben Schöbl's zu controliren, bestätigt die mit ausserordentlicher 
Die angeblichen Terminalkörperchen an den Haaren einiger Säugethiere. 275

Exactheit gegebene Darstellung Schöbl's in allen Puncten. Der Reichthum des Organs an Nervenfasern ist ein wahrhaft erstaunlicher. Uebrigens giebt es wohl kein Object, das sich so vorzüglich und bequem zur Demonstration von Nervenverästelungen und Nervenendkörperchen eignet, wie dieses."

Meiner Ansicht nach sind die eigenthümlichen Gebilde an den Haarwurzeln der genannten Säugethiere keine Terminalkörperchen, wie Schöbl und Boll meinen, sondern sogenannte $\mathrm{H}$ a arkeimje d. l. aus Zellen gebildete Fortsätze der Haarscheide (Wurzelscheide des Haars), welche dazu bestimmt sind zu einem neuen Ersatzhaar zu werden. - Es soll die Aufgabe dieser Zeilen sein, meine Behauptung gegenüber derjenigen von Schöbl, und Boll, Eingang und Verbreitung zu verschaffen.

Schöbl schildert die besagten Gebilde in der Flughaut der Fledermäuse in folgender Weise : unterhalb jeder Haarzwiebel liegt ein Terminalkörperchen, umschlossen von der Glashaut des Haarbalges. Das Körperchen hat die Gestalt eines kurzen Tannenzapfens mit etwas gerundeter Spitze; es besteht aus zwei Theilen; der Centraltheil oder Kern wird zusammengesetzt aus bisweilen pigmentirten Zellen, welche ihrer Genese nach den Zellen der Wurzelscheide, d.h. dem Rete Malpighii angehören; die Rinde bilden dicht gewundene oder verschlungene dunkelrandige Nervenfasern.

Aehnliche Gebilde hat Schöbl ferner am Ohr der Müuse entdeckt und beschrieben. Es heisst in dem oben citirten Aufsatz: "unter der Haarzwiebel in jedem Haarbalg befindet sich eine mehr oder weniger conische Verlängerung, welche aus deutlich kernhaltigen Zellen besteht, die ihrer Grösse nach der Wurzelscheide angehören. Der ganze Fortsatz ist von der Glashaut des Haarbalges umbüllt." Nach Schöbl's Mittheilung ziehen nun von den den Haarbalg umkreisenden Nervenfasern 2-4 Fasern längs der conischen Verlängerung nach abwärts bis an das stumpf abgestutzte Ende desselben und bilden daselbst einen kreisrunden oder ovalen Nervenknäuel, welcher fast unmittelbar unter dem betreffenden Fortsatz liegt. In einigen Fällen glaubte Schöbl im Innern des Knäuels einige wenige Zellen von der Beschaffenheit der Zellen des Fortsatzes gesehen zu haben.

Es existirt nach dieser Beschreibung zwischen den Körperchen bei der Fledermaus und denjenigen der Maus ein kleiner Unterschied, während bei der Fledermaus eine Anhäufung von Zellen des Rete Mal- 
pighii von Nervenfasern umsponnen wird, befinden sich bei der Hausmaus die aufgeknänelten Nervenfasern unterhalb des zelligen Fortsatzes derHaarscheide. Durch die den beiden Abhandlungen Schöb l's beigefïgten Abbildungen wird diese Beschreibung der Gebilde in entsprechender Weise illustrirt.

Schöbl hält nun die beschriebenen Gebilde für Endorgane der sensitiven Nerven, für sogenannte Terminalkörperchen und Boll schliesst sich ihm an.

Ich stimme im Wesentlichen der von Schöbl gelieferten Beschreibung bei, seiner Deutung durchaus nicht. Auch ich finde an den Haarwurzeln der Fledermäuse, der Hausmäuse und, wie ich hinzufügen kann, der Ratten und der Maulwürfe kugelige oder ovoide zellenhaltige Fortsätze der Haarscheide, welche von der Glashaut umgeben, in die Cutis hineinragen. Auch dass die Nervenfasern (und Blutgefässe) in reichlicher Menge zu jenem Fortsatz und dem Haarbalge hinzutreten, muss ich constatiren, wenngleich ich die regelmässigen Schlingen und Aufknäuelungen nicht so deutlich sah, als sie Schöbl zeichnet. In anderer Beziehung aber sind meine Resultate andere. Schöbl findet die Körperchen an allen Haaren der Flughaut der Fledermäuse und an allen Haaren des äussern Ohrs der Mäuse. Diesem muss ich widersprechen; ich habe mehr als einmal die Körperchen durchaus vermisst. Dagegen finde ich dieselben Gebilde sowohl bei den genannten Sängethieren, als auch bei anderen (Ratte, Maulwurf) an beliebigen Gegenden der Körperhaut, jedoch keineswegs bei allen Individuen.

Wie stimmt dieses inconstante und das verbreitete Vorkommen zu der Deutung der Körperchen als Endorganen sensitiver Nerven?

Ich meine, es erheben sich gewichtige Bedenken gegen die Auffassung der Körperchen als nervöse Terminalkörperchen von Seiten des Haars.

Wirft man einen Blick auf die von Schöbl gelieferten Abbildungen der Körperchen, so fällt etwas sofort auf, nämlich der Mangel ein er Haarpapille; an beiden Tafeln (Taf. IV Fledermaus, Taf. XXIV Maus) ist von einer Haarpapille nichts sichtbar, die Haarzwiebel besitzt diejenige Form, welche man seit Henle mit dem Namen Harkolben $z u$ bezeichnen pflegt. Henle schreibt in seiner Eingeweidelehre pag. 21: „die Haarwurzel erscheint in zweierlei Formen: offen und hohl, so lange das Haar wächst, oder geschlossen und solid, wenn das Haar seine typische 
Länge erreicht hat und sich zum Ausfallen anschickt." Ich hahe an einem andern Orte (Reicherts Archiv Jahrgang 1867 p. 517) auf die Richtigkeit dieser im Allgemeinen wenig gekannten und wenig berïcksichtigten Thatsachen aufmerksam gemacht. Es wird nun keinem Histologen, welchem die beiden Formen der Haarwurzel aus eigener Anschauung bekannt sind, entgehen, dass in den Abbildungen von Schöbl die Haarwurzel unzweifelhaft die Form des sogenannten Haarkolbens hat, d. h. eines Haars, welches sein Wachsthum vollendet hat. - Dass man an solchen mit einem Haarkolben versehenen Haaren jene Körperchen sitzen sieht, muss ich, wie bemerkt durchaus bestätigen. - Wie steht es aber mit der Anwesenheit der Körperchen an Haaren, welche auf einer Haarpapille sitzen? Hierauf giebt Schöbl direct keine Antwort; er hat die Körperchen an allen Haaren der betreffenden Körpergegenden jener Thiere gesehen. - Meine Untersuchungen geben mir eine Antwort: an denjenigen Haaren, welche eine of fene Harzwiebel und eine deutliche Haarpapille haben, finden sich niemals jene Körperchen.

Das Vorkommen der Körperchen an ausgewachsenen Haaren, das Fehlen derselben an noch wachsenden Haaren, das inconstante Vorkommen an Individuen derselben Species, und die Verbreitung über verschiedene Gegenden des Körpers -- spricht durchaus gegen die Auffassung der Körperchen als Nervenendorgane. Warum sollten einzelne Individuen aller Endorgane beraubt sein, während andere an jedem Haar der ganzen Körperoberfläche ein Endorgan besitzen?

In einer früheren Abhandlung über den Haarwechsel (Reicherts Archiv 1867 pag. 517-541) habe ich auf Grund angestellter Untersuchungen die Behauptung aufgestellt, dass beim $\mathrm{H}$ a a rw e chs $\mathrm{el}$ das neue Haar oder Ersatzhaar nach Atrophie der alten Haarpapille sich bilde aus einer Zellenanhäufung welche sich als ein in die Cutis hineinragender Fortsatz der den Haarkolben umgebenden Haarscheide darsteilt. Wenngleich meine Behauptung von Götte angegriffen worden ist und seither noch keine Bestätigung erfahren hat, so halte ich dennoch an derselben fest ${ }^{1}$ ).

Jene an der Haarwurzel befindlichen Körperchen lassen nun meiner Ansicht nach eine viel bequemere, leichtere und ungezwun-

1) Auf die zwischen Götte und mir existirenden Differenzen in Bezug nuf die Bildung der Haare gedenke ich in einer anderen Mittheilnng einzugehn. 
gene Erklärung zu, wenn ich sie - wie in dem früher citirten Aufsatz geschehen ist - mit dem Haarwechsel in directe Beziehung bringe. Damals schrieb ich (Reicherts Archiv 1867 pag. 529): "In ganz ähnlicher Weise, wie beim Rennthier, bildet sich das neue Haar beim Rind und beim Kalb, ferner bei Nagern (Mäusen und Ratten), doch sind wegen der Kleinheit der Haare bei letzteren die Vorgänge schwieriger zu verfolgen. Doch deuten die kleinen st a rk pigmentirten Anh änge, welche ich seitlich oder unten an jedem Haarbalg sitzen sah, und welche sich wie der abgeschnürte Grund des Haarbalgs ausnahmen, auf eine gleiche Entwicklungsweise."

Der aus Zellen des Rete Malpighii bestehende Fortsatz der Haarscheide bei den genannten Säugern ist eben ein Haarkeim, die Anlage eines neuen Haares; diese Auffassung stimmt sehr gut mit den ermittelten Thatsachen. - Hieraus erklärt es sich, dass die Körperchen nur an solchen Haaren sich finden, deren Wachsthum beendet ist und dass dieselben an noch wachsenden Haaren fehlen; hierzu passt die Thatsache, dass die Körperchen nicht allein auf die Flughaut der Fledermäuse und das äussere Ohr der Hausmäuse beschränkt sind, sondern sich auch an andern Körpergegenden und bei andern Säugern finden; hierdurch lässt es sich verstehen, warum bei einzelnen Individuen alle Haare mit jenen Körperchen versehen sind, bei anderen kein Haar ein solches Körperchen besitzt. Jene Individuen sind im Begriff ibre Haare zu wechseln, bei diesen ist der Wechsel beendigt und die Anlage des neuen Haares noch gar nicht vorhanden.

Zum Schluss noch die Bemerkung, dass die von Schöbl ermittelte Thatsache, dass Nervenfasern reichlich zu jenen Körperchen hinzutreten - welche Thatsache ich durchaus bestätigen muss, keineswegs gegen die Deutung der Körperchen als Haarkeime geltend gemacht werden darf, da der Eintritt von Nervenfasern in die Haarpapille eine unbestrittene Sache ist. Wie die Nerven in den Haarpapillen, resp. in den dieselbe umgebenden und den Haarbalg auskleidenden Zellen der Haarscheide enden, das zu untersuchen bleibt noch der weitern Forschung überlassen.

Dorpat, den 23. October 1871. 